\title{
Effect of Vitamin D in a Patient With Classical Adrenal Hyperplasia due to 11-Hydroxylase Deficiency
}

\author{
Nithin Thomas ${ }^{\mathrm{a}}$, Amir Kalani ${ }^{\mathrm{b}}$, Richard Vincent ${ }^{\mathrm{c}}$, Milay Luis Lam ${ }^{\mathrm{b}}$, Gul Bahtiyar ${ }^{\mathrm{a}}$, \\ Alejandra Borensztein ${ }^{\mathrm{d}}$, Efren Quinto $^{\mathrm{e}}$, Alan Sacerdote ${ }^{\mathrm{a}, \mathrm{f}}$
}

\begin{abstract}
Both classical and non-classical CAH, like PCOS, are characterized by insulin resistance (IR) and are also ameliorated by measures which reduce IR. Vitamin D supplementation reduces IR and ameliorates PCOS in Vitamin D deficient/insufficient (VDDI) patientsraising the question: would Vitamin D replacement also ameliorate CAH? Our patient is a 47 year old man with Type 2 diabetes (Type 2 $\mathrm{DM}$ ) and hypertension hospitalized for cellulitis, abscess, osteomyelitis, and gangrene of the left foot. He was not taking any known insulin sensitizers, and denied any history of acne or hyperpigmentation. The patient has no progeny and never had intercourse due to issues concerning his phallus size. He had hypospadias and micropenis at birth. The former was surgically corrected in childhood. His BMI $=36.45 \mathrm{~kg} / \mathrm{m}^{2}$ with a central fat distribution. On physical examination there was no acanthosis nigricans or hyperpigmentation. He had a stage IVa Hamilton male pattern alopecia that started during his early $20 \mathrm{~s}$. He had micropenis (or clitoromegaly), measuring $1.5-2 \mathrm{~cm}$ when flaccid; scrotum (or scrotalized labia majora) was normal in size. Testes is measured $3.4 \mathrm{~cm}$ in their long diameter and were firm. On 12-4-2012 his serum 11-deoxycortisol by liquid chromatography tandem mass spectrometry (LC MS/MS) was $2024 \mathrm{ng} / \mathrm{dL}(\leq 76)$ while his serum 25-OH-vitamin D by LC MS/ MS was $12 \mathrm{ng} / \mathrm{mL}(\geq 30)$, and his 1,25 (OH)2-Vitamin D3 by LC MS/MS was $\leq 8 \mathrm{pg} / \mathrm{mL}(18-72)$. Supplementation was begun with ergocalciferol 50,000 units orally weekly. Nine days later his serum 11-deoxycortisol fell to $425 \mathrm{ng} / \mathrm{dL}$, while serum 25-OH-Vitamin D
\end{abstract}

Manuscript accepted for publication July 5, 2013

${ }^{a}$ Division of Endocrinology, Woodhull Medical Center, 760 Broadway, Brooklyn, NY 11206, USA

${ }^{b}$ Division of Internal medicine, Woodhull Medical Center, 760

Broadway, Brooklyn, NY 11206, USA

${ }^{\mathrm{c} C}$ College of Liberal Arts, Hofstra University, 516 Harvard Avenue, Baldwin, NY 11510, USA

${ }^{\mathrm{d}}$ Department of Endocrinology, SUNY Downstate, 376 Broadway, Apt 11A, New York, NY 10013, USA

e Department of Surgery, Woodhull Medical Center, 760 Broadway, Brooklyn, NY 11206, USA

${ }^{\mathrm{f}}$ Corresponding author: Alan Sacerdote, Division of Endocrinology, Woodhull Medical Center, 760 Broadway, Brooklyn, NY 11206, USA. Email: Sacerdoa@nychhc.org

doi: http://dx.doi.org/10.4021/jmc1352w rose to $23 \mathrm{ng} / \mathrm{mL}$, and serum 1,25-(OH)2-Vitamin D3 remained $\leq 8$ $\mathrm{pg} / \mathrm{mL}$. Seventeen days later his serum 11-deoxycortisol was 194 $\mathrm{ng} / \mathrm{dL}$, while his serum 25-OH-Vitamin D was $27 \mathrm{ng} / \mathrm{mL}$, and his 1,25-(OH)2-vitamin D3 remained $\leq 8$ pg/mL. 28 days after starting supplementation with ergocalciferol the 11-deoxycortisol was $<$ $20 \mathrm{ng} / \mathrm{dL}$. The laboratory lost the corresponding sample for Vitamin D metabolites. His lymphocyte karyotype was XY. He refused any biopsies, which might have disclosed mosaicism.Vitamin D might be a means of treating classical 11-hydroxylasedeficiency in patients with a VDDI co-morbidity and suggest that it may work by reducing IR.

Keywords: 11-Hydroxylase deficiency; 11-Deoxycortisol; Vitamin $\mathrm{D}$; Insulin resistance

\section{Introduction}

Congenital Adrenal hyperplasia (CAH) is an autosomal dominant disorder with variable penetrance caused by a quantitative or functional deficiency of enzymes required for the synthesis of cortisol and/or aldosterone in the adrenal glands. The most common adrenal enzyme deficiency is 21-hydroxylase deficiency (21-OHD), while 11-hydroxylase deficiency (11OHD) accounts for approximately $5-8 \%$ of cases $[1,2]$. In the adrenal gland during the final step of cortisol synthesis, 11-hydroxylase converts 11- deoxycortisol (compound S) to cortisol. In patients with 11OHD, ACTH secretion from the pituitary is increased due to decreased negative feedback from cortisol on hypothalamic CRH secretion. This leads to formation of more cortisol precursors, which are then siphoned off towards androgen production leading to hyperandrogenism.

Patients with CAH are grouped into two major categories depending on the severity of the enzyme deficiency. There is a classical form in which symptoms are evident at birth with virilization and external genital ambiguity in female infants, hypertension in infants with classical 11-OHD, and salt-wasting with hypotension in some infants with classic 21-OHD [3]. There is also a non-classical form, which does not become apparent until later in life, since it is due to a milder mutation or to a more severe mutation that is heterozygously expressed. These patients usually present in 
11-Deoxycortisol (ng/dl) 25-OH-Vitamin D (ng/ml)

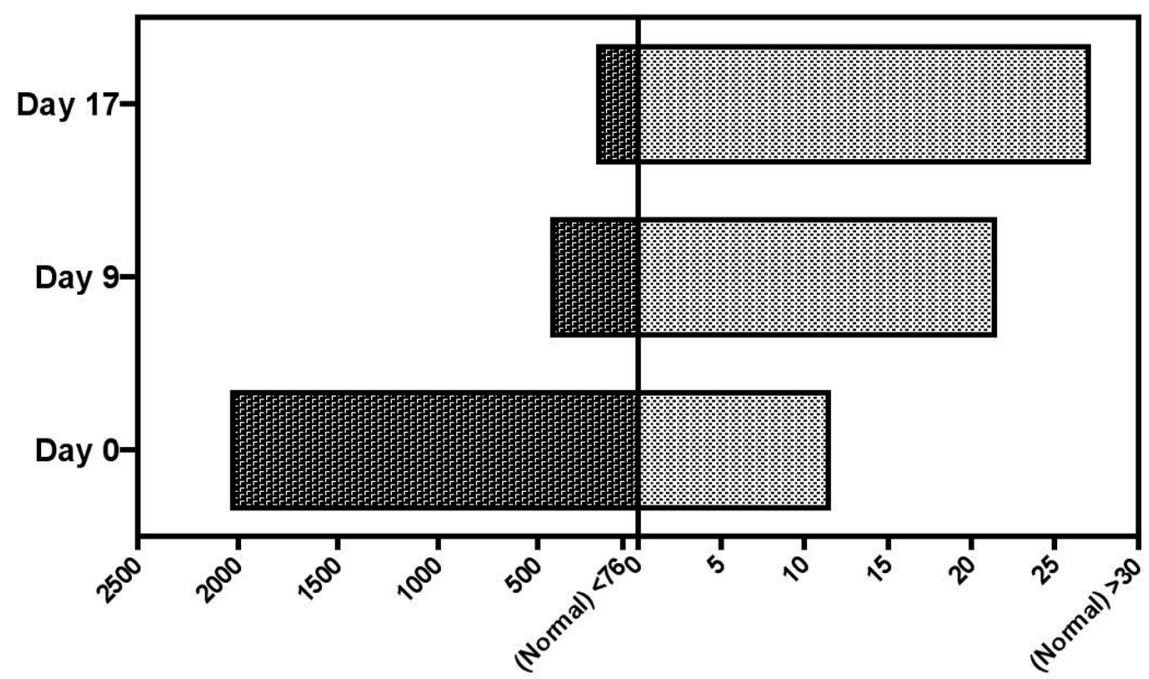

Figure 1. Changes in serum 11-deoxycortisol (left) as a function of changes in serum 25-OH-Vitamin D (right) at baseline and at 9 days and 17 days after starting ergocalciferol 50,000 IU daily.

mid-childhood, adolescence, or adulthood with acne, irregular menses, infertility, hirsutism, and precocious pubarche [4]. Additionally, $\mathrm{CAH}$ is also associated with conditions such as obesity, autoimmunity [5] and insulin resistance (IR) [6]. It has been reported that IR may also be associated with vitamin D deficiency [7].

In recent years, vitamin D deficiency has been recognized as a global concern [8]. $10-60 \%$ of all adults worldwide have vitamin D deficiency/insufficiency [8]. Vitamin D deficiency is currently defined as serum 25-hydroxyvitamin D (25(OH) D) levels less than $20 \mathrm{ng} / \mathrm{mL}$, while insufficiency is defined as levels between 20 to $30 \mathrm{ng} / \mathrm{mL}$, and severe deficiency at levels $<10 \mathrm{ng} / \mathrm{mL}$. Vitamin D replete is defined as values above $30 \mathrm{ng} / \mathrm{mL}$ due to lack of physiological (negative feedback) response of PTH to vitamin D at concentrations above this value in women [9]. Some of the purported non-classic benefits of Vitamin D, e.g. insulin sensitization and improved insulin secretion, anti-neoplastic, cardiovascular, and immunomodulatory may require somewhat higher levels of Vitamin D [10-17].

Vitamin D inadequacy has been associated with a variety of conditions such as, osteoporosis [18], falls [19] cardiovascular disease [20], systemic lupus erythematosus [21], diabetes mellitus type I [22], preeclampsia [23], multiple sclerosis [24], tuberculosis [25], breast cancer [26], and colorectal cancer [27]. Recent studies have also linked vitamin D deficiency to IR [28]. Various conditions that are associated with IR have also been reported to be affected by vitamin D levels [29-32]; of particular interest here is Polycystic Ovarian Syndrome (PCOS), which shares many features with NCAH, including IR [32].

These shared features include: hyperandrogenism, men- strual irregularities, hypofertility, polycystic ovaries, central obesity, acanthosis, skin tags, premature pubarche, and IR. Many interventions that ameliorate PCOS also improve the biochemical and clinical expression of NCAH. Recently, Vitamin D deficiency has been linked to more severe expression of PCOS symptoms and its supplementation has been shown to be beneficial in improving a variety of PCOS symptoms such as menstrual abnormalities and IR [32]. Although various studies have explored the role of vitamin D in the treatment of PCOS, the potential therapeutic value of vitamin D for congenital adrenal hyperplasia $(\mathrm{CAH})$ has not been extensively explored. In this case report, we present and discuss what appears to be the first reported case of classical $11 \mathrm{OHD}$ biochemically improved with vitamin D supplementation alone.

\section{Case Report}

Our patient is an obese 47 years old male (as per his own gender identification) with hypertension and diabetes mellitus type 2, who was hospitalized for cellulitis, abscess, osteomyelitis, and gangrene of the left foot. He does not have any progeny, but per him, he did not want any children. On further questioning he denied ever having had sexual relations. He denied any recent history of acne. On physical examination he is $178 \mathrm{~cm}\left(5^{\prime} 10^{\prime \prime}\right)$ tall and has a BMI of 36.45 $\mathrm{kg} / \mathrm{m}^{2}$ with a central fat distribution. He has a stage IVa Hamilton male pattern alopecia that started during his 20's [33].

There is no acanthosis nigricans or hyperpigmentation. $\mathrm{He}$ has microphallus (or clitoromegaly?), measuring $2.0 \mathrm{~cm}$ in length. His mother related that he underwent surgical cor- 
rection of hypospadias in early childhood. His testes were fully descended and measured $3.4 \mathrm{~cm}$ in their longer diameter. Since the patient refused scrotal ultrasound, we do not know if the testis were natural or prosthetic or if the "scrotum" contained adrenal rests. The patient's mother was unable to supply any additional information on this point.

On further investigation his unstimulated 0800 serum 11-deoxycortisol by liquid chromatography tandem mass spectroscopy (LC MS/MS) was $2024 \mathrm{ng} / \mathrm{dL}(\leq 76)$ while his serum 25OHD was $12 \mathrm{ng} / \mathrm{mL}(\geq 30)$ (Fig. 1). Unstimulated 0800 levels of 17-OH-progestesterone, 17-OH-pregnenolone, and deoxycorticosterone were normal. Supplementation was begun with ergocalciferol 50,000 units orally weekly. After 9 days his serum $25 \mathrm{OHD}$ rose to $23 \mathrm{ng} / \mathrm{mL}$ while his serum 11-deoxycortisol fell to $425 \mathrm{ng} / \mathrm{dL}$. Seventeen days after beginning supplementation his serum 25OHD further improved to $27 \mathrm{ng} / \mathrm{dL}$ while his 11-deoxycortisol improved to $194 \mathrm{ng} / \mathrm{dL}$ (Fig. 1). Twenty-nine days after starting ergocalciferol the 11-deoxycortisol level fell to $<20 \mathrm{ng} / \mathrm{dl}$; the sample for the corresponding 25-OHD was lost by the laboratory. We believed our patient might be a genetically female pseudohermaphrodite. A lymphocyte karyotype was performed, which was XY with normal G-band patterns within the limits of standard cytogenetic analysis. The following possibilities, although rare, could not be ruled out: low level mosaicism, very subtle rearrangements, and genetic disorders undetectable by standard cytogenetic methods. The patient declined further investigation, such as skin or testicular biopsy for karyotyping. He was subsequently discharged to a rehabilitation facility.

\section{Discussion}

In recent years there has been significant interest regarding "non-classic" roles of vitamin D after it was discovered that, in addition to kidneys, bone and gut, vitamin D receptors are also present in other tissues such as brain, prostate, breast, colon, adrenal cortex, and immune cells [11, 32, 34-36]. Since most tissues and cells in the body have a vitamin D receptor and 1, $25(\mathrm{OH}) 2 \mathrm{D}$ influences the expression levels along with other factors of up to one third of the human genome [37], an area that has been the focus of some research has been the relationship between vitamin D and IR. Animal studies have shown that supplementation of vitamin D increases secretion of insulin and improves insulin sensitivity [38]. Afsaneh et al. reported an inverse relation between fasting plasma glucose and basal $25(\mathrm{OH})$ vitamin D level, and only higher vitamin D concentrations of $40-60 \mathrm{ng} / \mathrm{mL}$ are associated with improvement in insulin sensitivity [39]. Inzucchi et al. reported increased insulin sensitivity in 54\% of 5677 subjects by vitamin D supplementation [40]. Additionally, various studies have shown that vitamin D supplementation in conditions that are associated with IR, such as diabetes type 2, metabolic syndrome, PCOS, and hepatitis $\mathrm{C}$, may be beneficial [29-32, 41]. In recent years, it has also been reported that CAH is also associated with IR [6, 42-46].

Non-classical 21-OHD is one of the most common autosomal disorders with the highest prevalence amongst Hispanics, eastern European Jews, and Mediterraneans [47] accounting for $90 \%$ of reported cases of NCAH. The disorder is due to mutations of the CYP21A2 gene located at chromosome 6p21 in the HLA locus. In 1951 Shepard and Clausen reported a less common type of CAH resulting from 11OHD, which is the type presented in this case report [3]. The incidence of $11 \mathrm{OHD}$ in the general population is $1 / 100,000$, while its frequency has been reported as high as 1/5000 in highly inbred populations such as Moroccan Jews [48].

Biochemically, classical 11OHD patients usually have baseline elevations of plasma ACTH, which then leads to increased formation of ACTH-stimulated cortisol precursors such as 11-deoxycortisol and others. Some of these precursors will then accumulate and subsequently are shunted off to the androgen synthesis pathway leading to elevated androgen levels. Clinically, the classical form of $11 \mathrm{OHD}$ often presents in newborn females with ambiguous genitalia and hypertension; male infants might have hypertension and appear excessively virilized, while the non-classic form presents later in life as precocious pubarche, hirsutism, acne, alopecia, infertility, and menstrual abnormalities. Final adult height may be compromised due to early epiphyseal closure.

Conventional treatment of $11 \mathrm{OHD}$ varies by age and sex, but is mainly focused on glucocorticoids, which inhibit the central secretion of corticotrophin releasing hormone $(\mathrm{CRH})$ and $\mathrm{ACTH}$, resulting in a decrease in androgen precursors and subsequent androgen synthesis. Treatment goals include normal linear growth velocity and "on-time" puberty in affected children. In adolescent and adult females treatment is aimed at regularization of menses, amelioration of hirsutism, acne, and alopecia, and restoration of fertility [49]. A consensus now recommends that hydrocortisone be used in the treatment of children with $\mathrm{CAH}$, rather than longacting glucocorticoids like dexamethasone [50-54]. Infants with ambiguous genitalia may undergo corrective surgery to render the phenotypic gender congruent with the chromosomal sex. Such surgery should be performed before the child's gender identity has been established. In pregnancies in which the offspring are at high risk for classical 21-OHD, pre-natal treatment with dexamethasone has been reported to be effective in preventing the birth of female babies with ambiguous genitalia [55-57]. Although glucocorticoid treatment (sometimes combined with fludrocortisone) continues to be the mainstay of conventional treatment of $\mathrm{CAH}$ and has been very helpful and lifesaving in that capacity, its use, even with recent refinements, continues to be plagued with issues regarding over- and under-treatment, growth inhibition, hypertension, obesity, low bone density, testicular adrenal rest 
tumors, and diabetes [58-60]. Our group has been focusing on insulin sensitizing interventions to reduce IR, which is a consistent feature of $\mathrm{CAH}$, as it is with PCOS [61-65].

It has been reported that $\mathrm{CAH}$ is associated with IR [6]. In vitro studies have shown that hyperinsulinemia may direct the adrenals toward androgen synthesis and away from cortisol production [66]. Charmandari et al. showed that children with $\mathrm{CAH}$, when compared to normal children matched for BMI, are more likely to have IR [44]. Recently, Finkielstain et al. conducted a cross-sectional study of 244 patients with both classical and non-classical adrenal hyperplasia and reported that IR was present in $38 \%$ and $20 \%$ of adults with classical and non-classical adrenal hyperplasia respectively, and furthermore, $61 \%$ of all these patients were vitamin D insufficient [46]. In this study assessment for insulin resistance was performed using only HOMA-IR, which reflects hepatic insulin resistance to a greater degree than peripheral (fat/muscle) insulin resistance. The role of vitamin D in PCOS, a condition that closely resembles $\mathrm{NCAH}$, has been the subject of extensive research in recent years.

Various studies have shown that Vitamin D supplementation may be beneficial in PCOS patients, possibly owing to its insulin sensitizing effect. Patra et al. showed that PCOS patients who were also vitamin $\mathrm{D}$ deficient had more severe IR [67]. This study demonstrated a strong inverse relationship between serum $25(\mathrm{OH})$ vitamin D level and obesity in PCOS patients, which may be explained by the storage of lipophilic $25(\mathrm{OH})$ vitamin $\mathrm{D}$ in adipose tissue. Vitamin D with calcium and metformin could be effective for the treatment of anovulation and oligomenorrhea in PCOS [68]. Selimoglu et al. treated 11 women with PCOS, nine of whom were vitamin D deficient, with single doses of vitamin D3 (300,000 IU) orally and showed a significant decrease in homeostasis model assessment (HOMA)-IR and serum androgen levels after only 3 weeks [69]. The precise mechanism behind vitamin D's effect on insulin sensitization is unknown, however, it has been suggested that it might be due to increased synthesis and release of insulin (which can reduce the IR secondary to glucose toxicity), enhanced insulin receptor expression (by regulating nuclear peroxisome proliferator activated receptor gamma [PPAR- $\gamma]$ ), an effect on calcium and phosphorous metabolism, or due to inhibition of inflammatory cytokines IL-1, IL-6, and TNF- $\alpha$ that may be involved in the development of IR [70].

Besides insulin sensitization, vitamin D has immunomodulatory effects. NCAH is also associated with autoimmunity [5]. Administration of the active vitamin D metabolite, calcitriol, ameliorates experimental autoimmune diseases such as type 1 diabetes and thyroiditis. On the molecular level 1, 25(OH2) D3 supplementation leads to decreased expression of HLA class 2 molecules on endocrine cells and inhibits $\mathrm{T}$ cell proliferation and secretion of cytokines. An effect of vitamin D on thymic education ('hormonal imprinting') has been reported in animals, which also contributes to its immunomodulatory properties. Vitamin D levels are lower in auto-immune hyperthyroidism than in non-autoimmune hyperthyroidism. Also Vitamin D supplementation in infancy was reported to be associated with a lower incidence of type 1 diabetes. The actions of $1,25(\mathrm{OH})$ $2 \mathrm{D} 3$ are mediated via the nuclear vitamin D receptor. Certain polymorphisms of its gene, located on chromosome 12q1214 , were found to be associated with autoimmune diseases such as type 1 diabetes, Graves' disease, Crohn's disease, rheumatoid arthritis, systemic lupus [17] and Addison's disease [35].

It has been also shown that Vitamin D deficiency leads to increased parathyroid hormone (PTH) levels. Increased PTH levels alone have been associated with increased testosterone, infertility, and IR, most of which are present in both NCAH and PCOS [32, 70, 71]. Bachelot et al. suggested that maintaining vitamin D sufficiency should be a goal for individuals with $\mathrm{CAH}$ [72]. Hence, $\mathrm{CAH}$ patients with vitamin D deficiency may benefit from vitamin D supplementation to reduce their symptoms and biochemical abnormalities, although evidence from randomized clinical trials is needed to confirm its possible therapeutic value. Here we reported a case in which vitamin D supplementation was associated with dramatically reduced 11-deoxycortisol levels in a patient with $110 \mathrm{HD}$ and vitamin D deficiency. We conclude that vitamin D supplementation might be an alternative means of treating $\mathrm{CAH}$ due to $11 \mathrm{OHD}$ in patients who also have vitamin D deficiency/insufficiency, and propose that it may work indirectly by reducing IR and by immunomodulation whereby any autoimmune assault on the steroidogenic machinery of the adrenal cortex may be ameliorated via reduction in cytokine production, downregulation of $\mathrm{T}$ cell proliferation, and downregulation of expression of HLAClass II molecules involved in the suppression of synthesis and activity of adrenal steroidogenic enzymes. Vitamin D supplementation may work directly in CAH via binding to the adrenocortical vitamin D receptors affecting the synthesis and expression of adrenocortical steroidogenic enzymes via cross-talk.

\section{Strengths of this study}

The dramatic and rapid reduction in serum 11-deoxycortisol associated with Vitamin D repletion.

\section{Limitations of this study}

1) Data is only available for one classical 11-OHD patient.

2) It is unknown if some of the likely improvement in insulin sensitivity in this patient with the resulting impressive decline in serum 11-deoxycortisol was due to factors other than Vitamin D repletion, e.g. control of infection via surgery and antibiotics as well as reduction in glycemia due to control of infection, nutritional therapy, and insulin, with a 
reduction in the IR resulting from glucose toxicity.

3 ) It is unknown whether our patient is a mosaic $\mathrm{XY} / \mathrm{XX}$ with ambiguous genitalia due to his classic 11-OHD or if the former are due to partial androgen resistance as seen in Reifenstein syndrome, or yet another etiology. Since biochemically our patient has classical 11-hydroxylase deficiency, it is not immediately apparent why his height $(178 \mathrm{~cm})$ was normal, as untreated patients generally have early epiphyseal closure and reduced adult height as a result of their hyperandrogenism. It is possible that if he has partial androgen resistance, his skeleton is also androgen resistant and thus, not susceptible to early epiphyseal closure. Growth is reported to be normal in XY children with androgen resistance and adult stature is reported to be normal for adult males and tall for adult females suggesting a putative Y-linked gene function which affects growth independently of testosterone [73].

\section{Teaching points}

Vitamin D repletion may result in dramatic and rapid biochemical improvement in classical 11-OHD patients who are also Vitamin D deficient.

The biochemical response seen is supportive of the concept that IR is pivotal in the expression of CAH and that treatments directed at IR may provide normalization of abnormal steroid metabolite levels without resulting in glucocorticoid side effects.

\section{References}

1. Soardi FC, Penachioni JY, Justo GZ, Bachega TA, Inacio $\mathrm{M}$, Mendonca BB, de Castro M, et al. Novel mutations in CYP11B1 gene leading to 11 beta-hydroxylase deficiency in Brazilian patients. J Clin Endocrinol Metab. 2009;94(9):3481-3485.

2. Ye ZQ, Zhang MN, Zhang HJ, Jiang JJ, Li XY, Zhang KQ. A novel missense mutation, GGC(Arg454) --> TGC(Cys), of CYP11B1 gene identified in a Chinese family with steroid 11beta-hydroxylase deficiency. Chin Med J (Engl). 2010;123(10):1264-1268.

3. Shepard TH, Clausen SW. Case of adrenogenital syndrome with hypertension treated with cortisone. Pediatrics. 1951;8(6):805-811.

4. Speiser PW. Nonclassic adrenal hyperplasia. Rev Endocr Metab Disord. 2009;10(1):77-82.

5. Parlato F, Pisano G, Misiano G, Cosentini E, Cacciapuoti C, Cavalcanti MR, Brai M, et al. HLADR5 and C4BQO high frequency and antinuclear antibodies positivity in patients with 21 hydroxylase deficiency from Campania region. J Endocrinol Invest. 1992;15(6):429-436.

6. Arlt W, Willis DS, Wild SH, Krone N, Doherty EJ, Hahner S, Han TS, et al. Health status of adults with congenital adrenal hyperplasia: a cohort study of 203 patients. J Clin Endocrinol Metab. 2010;95(11):51105121.

7. Pilz S, Kienreich K, Rutters F, de Jongh R, van Ballegooijen AJ, Grubler M, Tomaschitz A, et al. Role of vitamin $\mathrm{D}$ in the development of insulin resistance and type 2 diabetes. Curr Diab Rep. 2013;13(2):261-270.

8. Prentice A. Vitamin D deficiency: a global perspective. Nutr Rev. 2008;66(10 Suppl 2):S153-164.

9. Holick MF, Siris ES, Binkley N, Beard MK, Khan A, Katzer JT, Petruschke RA, et al. Prevalence of Vitamin $\mathrm{D}$ inadequacy among postmenopausal North American women receiving osteoporosis therapy. J Clin Endocrinol Metab. 2005;90(6):3215-3224.

10. Bikle D. Nonclassic actions of vitamin D. J Clin Endocrinol Metab. 2009;94(1):26-34.

11. Chiang KC, Chen TC. The Anti-cancer Actions of Vitamin D. Anticancer Agents Med Chem. 2013;13(1):126139.

12. Haq S, Ali S, Mohammad R, Sarkar FH. The complexities of epidemiology and prevention of gastrointestinal cancers. Int J Mol Sci. 2012;13(10):12556-12572.

13. Nemazannikova N, Antonas K, Dass CR. Role of vitamin D metabolism in cutaneous tumour formation and progression. J Pharm Pharmacol. 2013;65(1):2-10.

14. Weinstein SJ, Mondul AM, Kopp W, Rager H, Virtamo J, Albanes D. Circulating 25-hydroxyvitamin D, vitamin D-binding protein and risk of prostate cancer. Int J Cancer. 2013;132(12):2940-2947.

15. Cutolo $M$. The challenges of using vitamin $D$ in cancer prevention and prognosis. Isr Med Assoc J. 2012;14(10):637-639.

16. Hewison M. An update on vitamin D and human immunity. Clin Endocrinol (Oxf). 2012;76(3):315-325.

17. Gillian R. Hart. Medical conditions associated with Vitamin D deficiency and the clinical consequences. Review series. $2004 \mathrm{Sept} ; 1: 1-10$.

18. Holick MF. Vitamin D deficiency. N Engl J Med. 2007;357(3):266-281.

19. Broe KE, Chen TC, Weinberg J, Bischoff-Ferrari HA, Holick MF, Kiel DP. A higher dose of vitamin d reduces the risk of falls in nursing home residents: a randomized, multiple-dose study. J Am Geriatr Soc. 2007;55(2):234239.

20. Kendrick J, Targher G, Smits G, Chonchol M. 25-Hydroxyvitamin D deficiency is independently associated with cardiovascular disease in the Third National Health and Nutrition Examination Survey. Atherosclerosis. 2009;205(1):255-260.

21. Cutolo M, Otsa K. Review: vitamin D, immunity and lupus. Lupus. 2008;17(1):6-10.

22. Hypponen E, Laara E, Reunanen A, Jarvelin MR, Virtanen SM. Intake of vitamin D and risk of type 1 diabetes: a birth-cohort study. Lancet. 2001;358(9292):15001503. 
23. Bodnar LM, Catov JM, Simhan HN, Holick MF, Powers RW, Roberts JM. Maternal vitamin D deficiency increases the risk of preeclampsia. J Clin Endocrinol Metab. 2007;92(9):3517-3522.

24. Munger KL, Levin LI, Hollis BW, Howard NS, Ascherio A. Serum 25-hydroxyvitamin D levels and risk of multiple sclerosis. JAMA. 2006;296(23):2832-2838.

25. Yang HF, Zhang ZH, Chang ZQ, Tang KL, Lin DZ, Xu JZ. Vitamin D deficiency affects the immunity against Mycobacterium tuberculosis infection in mice. Clin Exp Med. 2012.

26. Garland CF, Gorham ED, Mohr SB, Grant WB, Giovannucci EL, Lipkin M, Newmark H, et al. Vitamin D and prevention of breast cancer: pooled analysis. J Steroid Biochem Mol Biol. 2007;103(3-5):708-711.

27. Holick MF. Calcium plus vitamin D and the risk of colorectal cancer. N Engl J Med. 2006;354(21):22872288; author reply 2287-2288.

28. Mezza T, Muscogiuri G, Sorice GP, Prioletta A, Salomone E, Pontecorvi A, Giaccari A. Vitamin D deficiency: a new risk factor for type 2 diabetes? Ann Nutr Metab. 2012;61(4):337-348.

29. Liu E, Meigs JB, Pittas AG, Economos CD, McKeown NM, Booth SL, Jacques PF. Predicted 25-hydroxyvitamin D score and incident type 2 diabetes in the Framingham Offspring Study. Am J Clin Nutr. 2010;91(6):16271633.

30. Scragg R, Sowers M, Bell C. Serum 25-hydroxyvitamin $\mathrm{D}$, diabetes, and ethnicity in the Third National Health and Nutrition Examination Survey. Diabetes Care. 2004;27(12):2813-2818.

31. Pittas AG, Sun Q, Manson JE, Dawson-Hughes B, Hu FB. Plasma 25-hydroxyvitamin D concentration and risk of incident type 2 diabetes in women. Diabetes Care. 2010;33(9):2021-2023.

32. Thomson RL, Spedding S, Buckley JD. Vitamin D in the aetiology and management of polycystic ovary syndrome. Clin Endocrinol (Oxf). 2012;77(3):343-350.

33. Hamilton JB. Patterned loss of hair in man; types and incidence. Ann N Y Acad Sci. 1951;53(3):708-728.

34. Sung CC, Liao MT, Lu KC, Wu CC. Role of vitamin $\mathrm{D}$ in insulin resistance. J Biomed Biotechnol. 2012;2012(634195.

35. Pani MA, Seissler J, Usadel KH, Badenhoop K. Vitamin $\mathrm{D}$ receptor genotype is associated with Addison's disease. Eur J Endocrinol. 2002;147(5):635-640.

36. Lundqvist J, Norlin M, Wikvall K. 1alpha,25-Dihydroxyvitamin D3 affects hormone production and expression of steroidogenic enzymes in human adrenocortical NCI-H295R cells. Biochim Biophys Acta. 2010;1801(9):1056-1062.

37. Holick MF, Binkley NC, Bischoff-Ferrari HA, Gordon CM, Hanley DA, Heaney RP, Murad MH, et al. Evaluation, treatment, and prevention of vitamin $\mathrm{D}$ deficiency: an Endocrine Society clinical practice guideline. J Clin Endocrinol Metab. 2011;96(7):1911-1930.

38. Tai K, Need AG, Horowitz M, Chapman IM. Vitamin $\mathrm{D}$, glucose, insulin, and insulin sensitivity. Nutrition. 2008;24(3):279-285.

39. Talaei A, Mohamadi M, Adgi Z. The effect of vitamin $\mathrm{D}$ on insulin resistance in patients with type 2 diabetes. Diabetol Metab Syndr. 2013;5(1):8.

40. Inzucchi SE, Maggs DG, Spollett GR, Page SL, Rife FS, Walton V, Shulman GI. Efficacy and metabolic effects of metformin and troglitazone in type II diabetes mellitus. N Engl J Med. 1998;338(13):867-872.

41. Tillmann HL. Vitamins? The magic bullet against hepatitis C. Expert Rev Anti Infect Ther. 2012;10(11):12731277.

42. Speiser PW, Serrat J, New MI, Gertner JM. Insulin insensitivity in adrenal hyperplasia due to nonclassical steroid 21-hydroxylase deficiency. J Clin Endocrinol Metab. 1992;75(6):1421-1424.

43. Saygili F, Oge A, Yilmaz C. Hyperinsulinemia and insulin insensitivity in women with nonclassical congenital adrenal hyperplasia due to 21-hydroxylase deficiency: the relationship between serum leptin levels and chronic hyperinsulinemia. Horm Res. 2005;63(6):270-274.

44. Charmandari E, Weise M, Bornstein SR, Eisenhofer G, Keil MF, Chrousos GP, Merke DP. Children with classic congenital adrenal hyperplasia have elevated serum leptin concentrations and insulin resistance: potential clinical implications. J Clin Endocrinol Metab. 2002;87(5):2114-2120.

45. Mnif MF, Kamoun M, Mnif F, Charfi N, Kallel N, Ben Naceur B, Rekik N, et al. Long-term outcome of patients with congenital adrenal hyperplasia due to 21-hydroxylase deficiency. Am J Med Sci. 2012;344(5):363-373.

46. Finkielstain GP, Kim MS, Sinaii N, Nishitani M, Van Ryzin C, Hill SC, Reynolds JC, et al. Clinical characteristics of a cohort of 244 patients with congenital adrenal hyperplasia. J Clin Endocrinol Metab. 2012;97(12):44294438.

47. White PC, Speiser PW. Congenital adrenal hyperplasia due to 21-hydroxylase deficiency. Endocr Rev. 2000;21(3):245-291.

48. White PC, Dupont J, New MI, Leiberman E, Hochberg Z, Rosler A. A mutation in CYP11B1 (Arg-448---His) associated with steroid 11 beta-hydroxylase deficiency in Jews of Moroccan origin. J Clin Invest. 1991;87(5):1664-1667.

49. Witchel SF, Azziz R. Nonclassic congenital adrenal hyperplasia. Int J Pediatr Endocrinol. 2010;2010(625105.

50. Bonfig W, Schmidt H, Schwarz HP. Growth patterns in the first three years of life in children with classical congenital adrenal hyperplasia diagnosed by newborn screening and treated with low doses of hydrocortisone. Horm Res Paediatr. 2011;75(1):32-37. 
51. Aycan Z, Akbuga S, Cetinkaya E, Ocal G, Berberoglu M, Evliyaoglu O, Adiyaman P. Final height of patients with classical congenital adrenal hyperplasia. Turk J Pediatr. 2009;51(6):539-544.

52. Merke D, Kabbani M. Congenital adrenal hyperplasia: epidemiology, management and practical drug treatment. Paediatr Drugs. 2001;3(8):599-611.

53. Bonfig W, Pozza SB, Schmidt H, Pagel P, Knorr D, Schwarz HP. Hydrocortisone dosing during puberty in patients with classical congenital adrenal hyperplasia: an evidence-based recommendation. J Clin Endocrinol Metab. 2009;94(10):3882-3888.

54. Speiser PW, Azziz R, Baskin LS, Ghizzoni L, Hensle TW, Merke DP, Meyer-Bahlburg HF, et al. Congenital adrenal hyperplasia due to steroid 21-hydroxylase deficiency: an Endocrine Society clinical practice guideline. J Clin Endocrinol Metab. 2010;95(9):4133-4160.

55. Vos AA, Bruinse HW. Congenital adrenal hyperplasia: do the benefits of prenatal treatment defeat the risks? Obstet Gynecol Surv. 2010;65(3):196-205.

56. Lajic S, Nordenstrom A, Ritzen EM, Wedell A. Prenatal treatment of congenital adrenal hyperplasia. Eur J Endocrinol. 2004;151(Suppl 3):U63-69.

57. Pang SY, Pollack MS, Marshall RN, Immken L. Prenatal treatment of congenital adrenal hyperplasia due to 21-hydroxylase deficiency. N Engl J Med. 1990;322(2):111115.

58. Loechner KJ, Patel S, Fordham L, McLaughlin JT. Decreased bone mineral density and vertebral compression fractures in a young adult male with 21-hydroxylase deficiency congenital adrenal hyperplasia (CAH): is $\mathrm{CAH}$ an unrecognized population at risk for glucocorticoidinduced osteoporosis? J Pediatr Endocrinol Metab. 2010;23(1-2):179-187.

59. Sciannamblo M, Russo G, Cuccato D, Chiumello G, Mora S. Reduced bone mineral density and increased bone metabolism rate in young adult patients with 21-hydroxylase deficiency. J Clin Endocrinol Metab. 2006;91(11):4453-4458.

60. Nebesio TD, Eugster EA. Growth and reproductive outcomes in congenital adrenal hyperplasia. Int $\mathrm{J}$ Pediatr Endocrinol. 2010;2010:298937.

61. Bahtiyar G, Sacerdote A. Management Approaches to Congenital Adrenal Hyperplasia in Adolescents and Adults; Latest Therapeutic Developments. In Amenorrhea 2011; Intech (Rijeka, Croatia), Amar Chaterjee, editor: $65-90$.

62. Mapas-Dimaya AC, Agdere L, Bahtiyar G, Mejia JO, Sacerdote AS. Metformin-responsive classic salt-losing congenital adrenal hyperplasia due to 21-hydroxylase deficiency: a case report. Endocr Pract. 2008;14(7):889891.

63. Bahtiyar G, Weiss K, Sacerdote AS. Novel endocrine disrupter effects of classic and atypical antipsychotic agents and divalproex: induction of adrenal hyperandrogenism, reversible with metformin or rosiglitazone. Endocr Pract. 2007;13(6):601-608.

64. Kalani A, Bahtiyar G, Sacerdote A. Ashwagandha root in the treatment of non-classical adrenal hyperplasia. BMJ Case Rep. 2012;2012

65. Kalani A, Thomas N, Sacerdote A, Bahtiyar G. Rouxen-Y gastric bypass in the treatment of non-classic congenital adrenal hyperplasia due to 11-hydroxylase deficiency. BMJ Case Rep. 2013;2013

66. Kelly SN, McKenna TJ, Young LS. Modulation of steroidogenic enzymes by orphan nuclear transcriptional regulation may control diverse production of cortisol and androgens in the human adrenal. J Endocrinol. 2004;181(2):355-365.

67. Patra SK, Nasrat H, Goswami B, Jain A. Vitamin D as a predictor of insulin resistance in polycystic ovarian syndrome. Diabetes Metab Syndr. 2012;6(3):146-149.

68. Rashidi B, Haghollahi F, Shariat M, Zayerii F. The effects of calcium-vitamin D and metformin on polycystic ovary syndrome: a pilot study. Taiwan J Obstet Gynecol. 2009;48(2):142-147.

69. Selimoglu H, Duran C, Kiyici S, Ersoy C, Guclu M, Ozkaya G, Tuncel E, et al. The effect of vitamin D replacement therapy on insulin resistance and androgen levels in women with polycystic ovary syndrome. J Endocrinol Invest. 2010;33(4):234-238.

70. Alemzadeh R, Kichler J. Parathyroid hormone is associated with biomarkers of insulin resistance and inflammation, independent of vitamin D status, in obese adolescents. Metab Syndr Relat Disord. 2012;10(6):422-429.

71. Panidis D, Balaris C, Farmakiotis D, Rousso D, Kourtis A, Balaris V, Katsikis I, et al. Serum parathyroid hormone concentrations are increased in women with polycystic ovary syndrome. Clin Chem. 2005;51(9):16911697.

72. Bachelot A, Chakthoura Z, Rouxel A, Dulon J, Touraine P. Classical forms of congenital adrenal hyperplasia due to 21-hydroxylase deficiency in adults. Horm Res. 2008;69(4):203-211.

73. Smith DW, Marokus R, Graham JM, Jr. Tentative evidence of Y-linked statural gene(s). Growth in the testicular feminization syndrome. Clin Pediatr (Phila). 1985;24(4):189-192. 